OPEN ACCESS

Edited by:

Wencai Zhang,

Virginia Tech, United States

Reviewed by:

Jotheeswari Kothandaraman,

Pacific Northwest National Laboratory

(DOE), United States

Junwei Han,

Central South University, China

*Correspondence:

Zhifeng Xu

xzf_1@163.com

Ruixiang Wang

wrx9022@163.com

Specialty section

This article was submitted to Green and Sustainable Chemistry,

a section of the journal

Frontiers in Chemistry

Received: 08 August 2020 Accepted: 08 December 2020 Published: 20 January 2021

Citation:

Yan K, Liu L, Zhao H, Tian L, Xu Z and Wang R (2021) Study on Extraction Separation of Thioarsenite Acid in Alkaline Solution by $\mathrm{CO}_{3}^{2-}$-Type

Tri-n-Octylmethyl-Ammonium Chloride. Front. Chem. 8:592837. doi: $10.3389 /$ fchem.2020.592837

\section{Study on Extraction Separation of Thioarsenite Acid in Alkaline Solution by $\mathrm{CO}_{3}^{2-}$-Type Tri-n-Octylmethyl-Ammonium Chloride}

\author{
Kang Yan ${ }^{1}$, Liping Liu ${ }^{1}$, Hongxing Zhao ${ }^{1}$, Lei Tian ${ }^{1,2}$, Zhifeng $X u^{3 *}$ and Ruixiang Wang ${ }^{1 *}$ \\ ${ }^{1}$ School of Metallurgical Engineering, Jiangxi University of Science and Technology, Ganzhou, China, ${ }^{2}$ Henan Yuguang Gold \\ and Lead Group Co., Ltd., Jiyuan, China, ${ }^{3}$ President Office, Jiangxi College of Applied Technology, Ganzhou, China
}

To overcome the problem of arsenic separation and enrichment from an alkaline leaching solution in arsenic-containing dust, a $\mathrm{CO}_{3}^{2-}$-type tri-n-octylmethyl-ammonium chloride (TOMAC) method for extracting thioarsenite is proposed in this paper. Considering an alkaline leaching solution as the research object, after vulcanization pretreatment, TOMAC transformation and organic phase saturated extraction capacity were measured, and the extraction mechanism was preliminarily studied. First, $\mathrm{Cl}^{-}$-type quaternary ammonium salt was effectively transformed to $\mathrm{HCO}_{3}^{-}$-type by treating organic phase with saturated $\mathrm{NaHCO}_{3 \text { five }}$ times. TOMAC was effectively transformed from $\mathrm{HCO}_{3}^{-}$to $\mathrm{CO}_{3}^{2-}$ type by alkaline washing with $1.0 \mathrm{~mol} / \mathrm{I} \mathrm{NaOH}$ solution; this washing was repeated thrice. Thereafter, the effects of organic phase composition, phase ratio, extraction time, and temperature on the extraction and separation of arsenic were investigated. The results show that under the conditions of $30 \% \mathrm{CO}_{3}^{2-}$-type TOMAC $+15 \%$ sec-octanol $+55 \%$ sulfonated kerosene, $V_{O} N_{A}=1 / 1$, and 5 min extraction at room temperature, the single-stage extraction rate of $A s^{\text {III }}$ is $85.2 \%$. The As ${ }^{\text {III }}$ concentration in raffinate can be reduced to less than $1.33 \times 10^{-3} \mathrm{~mol} / \mathrm{l}$ by four-stage countercurrent extraction, and the extraction rate of As ${ }^{\text {III }}$ can exceed $98.4 \%$.

Keywords: extraction separation, thioarsenite acid, alkaline solution, $\mathrm{CO}_{3}^{2-}-$ type, tri-n-octylmethyl-ammonium chloride

\section{INTRODUCTION}

Arsenic and its compounds are volatile. Arsenic is mainly concentrated in smelting dust, owing to the high-temperature volatilization, airflow movement, and mechanical inclusion during the smelting process of heavy non-ferrous metals, such as copper, lead, and zinc (Christof Lanzerstorfer, 2016). Arsenite or subarsenite is formed by the collision and adsorption of arsenic with lead, antimony, zinc, and other elements in high-temperature gas. The content of arsenic has a wide range from 10 to $40 \%$ (Jarošíková et al., 2018). Besides arsenic, high arsenic dust also contains a large amount of valuable metals, such as copper, lead, zinc, tin, and indium, which have high economic value (Asanov et al., 2016). High arsenic dust has the environmental characteristics of large production and high toxicity. 
The arsenic content in smelting dust is volatile, which has the characteristics of large production and high toxicity. Therefore, it is necessary to efficiently separate arsenic from smelting dust for further recycling (Ermolin et al., 2019). There have been many studies on arsenic removal from smelting dust, including roasting, leaching, and combined pyrohydrometallurgical processes. Arsenic removal by calcination serves mainly to volatilize arsenic in the form of arsenic trioxide in materials containing arsenic at high temperature, separate it from other valuable metals, and then obtain crude arsenic trioxide products through condensation and dust collection (Montenegro et al., 2013).

Arsenic is extracted from copper dust by leaching process; leaching can be classified as hot water leaching, acid leaching, and alkaline leaching according to the properties of leaching solution (Guo et al., 2016). The following methods for separating and enriching arsenic from leaching liquid include evaporation concentration crystallization, lime precipitation, ferric salt precipitation, sodium sulfide precipitation, adsorption, and solvent extraction (Hoffmann, 1993; Sanchez de la Campa et al., 2008; Morales et al., 2010). Sahu et al. investigated the acid leaching of copper from the soot of electrostatic precipitator (ESP) liner used in a copper smelter plant. Results showed that the acid concentration of $1.5 \mathrm{M}$ and pulp density of $20 \%$ was found to be optimum, and the leaching efficiency of copper was $97 \%$ at $97^{\circ} \mathrm{C}$ (Sahu et al., 2012).

To achieve the resource utilization of flue dust, most copper smelters send flue dust and copper concentrate directly back to the smelting system, which greatly increases the content of impurities (especially arsenic) in the flash-smelting furnace. The Kosaka smelter in Japan has been operated with the openprocess hydrometallurgical treatment for flue dust since 1975. This process involves recovering copper and zinc from the flue dust leaching solution and lead from the leaching slag. Similarly, most studies in this area have adopted the combined process of "hydro and pyro metallurgy" to treat the flue dust, i.e., to leach copper and zinc using water or dilute sulfuric acid and recover lead from the leaching slag through reduction smelting.

Karimov et al. studied the sulfuric acid leaching of dust left over from the reduction smelting at the Middle Ural Copper Smelter. The results showed that the optimum parameters for leaching dust were a temperature of $60^{\circ} \mathrm{C}$ and an initial acid concentration of $25 \mathrm{~g} / \mathrm{dm}^{3}$. Performing the leaching operation with these parameters maximizes the yields of arsenic, copper, and zinc (98\% As, 39\% Cu, and 82\% Zn) (Karimov and Naboichenko, 2016). Yang et al. reported the recovery of metals from copper smelting dust via $\mathrm{H}_{2} \mathrm{SO}_{4}$ and $\mathrm{H}_{2} \mathrm{O}_{2}$ leaching. Under optimum conditions, the leaching efficiencies achieved for $\mathrm{Cu}$, As, Fe, Cd, and $\mathrm{Zn}$ were 93.4, 94.2, 39.7, 98.1, and 90.7\%, respectively (Yang et al., 2017). Liu et al. investigated the metal extraction from copper smelting dust using oxidation leaching and the control of potential technology. The results showed that under the conditions of an $\mathrm{H}_{2} \mathrm{O}_{2}$ dosage of $0.8 \mathrm{ml} / \mathrm{g}$ (redox potential is $429 \mathrm{mV}), \mathrm{H}_{2} \mathrm{O}_{2}$ feeding speed of $1.0 \mathrm{ml} / \mathrm{min}$, initial $\mathrm{H}_{2} \mathrm{SO}_{4}$ concentration of $1.0 \mathrm{~mol} / \mathrm{l}$, initial $\mathrm{HCl}$ concentration of $1.0 \mathrm{~mol} / \mathrm{l}$, leaching temperature of $80^{\circ} \mathrm{C}$, initial liquid-tosolid ratio of $5: 1 \mathrm{ml} / \mathrm{g}$, and leaching time of $1.5 \mathrm{~h}$, copper and arsenic can be effectively leached from copper smelting dust, leaving residue as a suitable lead resource. The average leaching efficiencies of copper, arsenic, and iron were 95.27, 96.82, and $46.65 \%$, respectively (Liu et al., 2018). Xu et al. studied pressureleaching technology in the treatment of high-copper and higharsenic dust. At a liquid-to-solid ratio $(\mathrm{ml} / \mathrm{g})$ of $5: 1$, a leaching temperature of $453 \mathrm{~K}$, a retention time of $2 \mathrm{~h}$, an initial sulfuric acid concentration of $0.74 \mathrm{~mol} / \mathrm{l}$, an oxygen partial pressure of 0.7 $\mathrm{MPa}$, and an agitation speed of $500 \mathrm{r} / \mathrm{min}, 95 \%$ of copper, $99 \%$ of zinc, and only $6 \%$ of iron in the dust were leached, whereas $\sim 20 \%$ of arsenic was also leached. The leaching technique was optimized further to restrain the leaching of arsenic through the addition of a small amount of ferrous iron into the leaching system $[c(\mathrm{Fe}(2+))=0.036 \mathrm{~mol} / \mathrm{l}]$ (Xu et al., 2010).

While extracting arsenic from flue dust using dilute acid, significant dispersibility can be observed; $\sim 50 \%$ of arsenic enters the solution, whereas the other half enters the slag. The chemical precipitation of arsenic in the leaching solution can result in a loss of valuable metals, whereas the landfilling and stockpiling of the arsenic slag can result in potential secondary pollution. Consequently, the separation and enrichment of arsenic using the traditional extraction process is low; therefore, it is not suitable for the resource utilization and harmless disposal of high arsenic flue dust.

In contrast, arsenic oxides and arsenates are easily soluble in alkaline medium, based on which some studies have proposed the use of alkaline leaching to achieve arsenic concentration in the water phase. Reynolds et al. carried out $\mathrm{NaOH}$ leaching on the pressure-leaching slag of copper smelting dust (arsenic and iron slag), reaching an arsenic leaching rate of $88.3 \%$ (Reynolds, 1981). Furthermore, the $\mathrm{NaOH}-\mathrm{Na}_{2} \mathrm{~S}$ alkaline leaching process for the oxidation leaching of high arsenic flue dust led to an arsenic leaching rate of greater than $90 \%$ (Liu et al., 2009). Rappas et al. adopted a two-stage alkaline leaching process to effectively separate arsenic from lead and bismuth (Rappas et al., 1990). In fact, for high arsenic materials (e.g., arsenic sulfide slag), alkaline leaching is equally effective in arsenic removal (Zheng et al., 2008).

Although the effective separation of arsenic and the treatment of valuable metals can be achieved by alkaline leaching, how to recycle the alkali liquor and enrich arsenic efficiently to facilitate a final harmless disposal are the key difficulties. Therefore, a new process has been proposed; this process involves closed alkaline leaching, double-sulfuration synergistic solvent extraction, dearsenic-lime cascade precipitation, and arsenic-carbon thermal reduction for high arsenic copper smelting ash (as shown in Figure 1).

Based on previous experimental studies (Xu et al., 2016), the sulfurized products of arsenous acid under alkaline conditions are mainly $\mathrm{HAsO}_{2} \mathrm{~S}^{2-}$ and $\mathrm{HAsOS}_{2}^{2-}$; however, there are currently still some limitations on the extraction and stripping of thioarsenite in alkaline solutions. In alkaline media, arsenic exists in the form of thioarsenite anions, and quaternary ammonium salt is a strong base salt, which contains $\mathrm{R}_{4} \mathrm{~N}^{+}$groups to extract complex anion (Guan and Zhang, 2011). Therefore, herein, experiments on the extraction and stripping of thioarsenite in $\mathrm{NaOH}$ solutions were conducted 


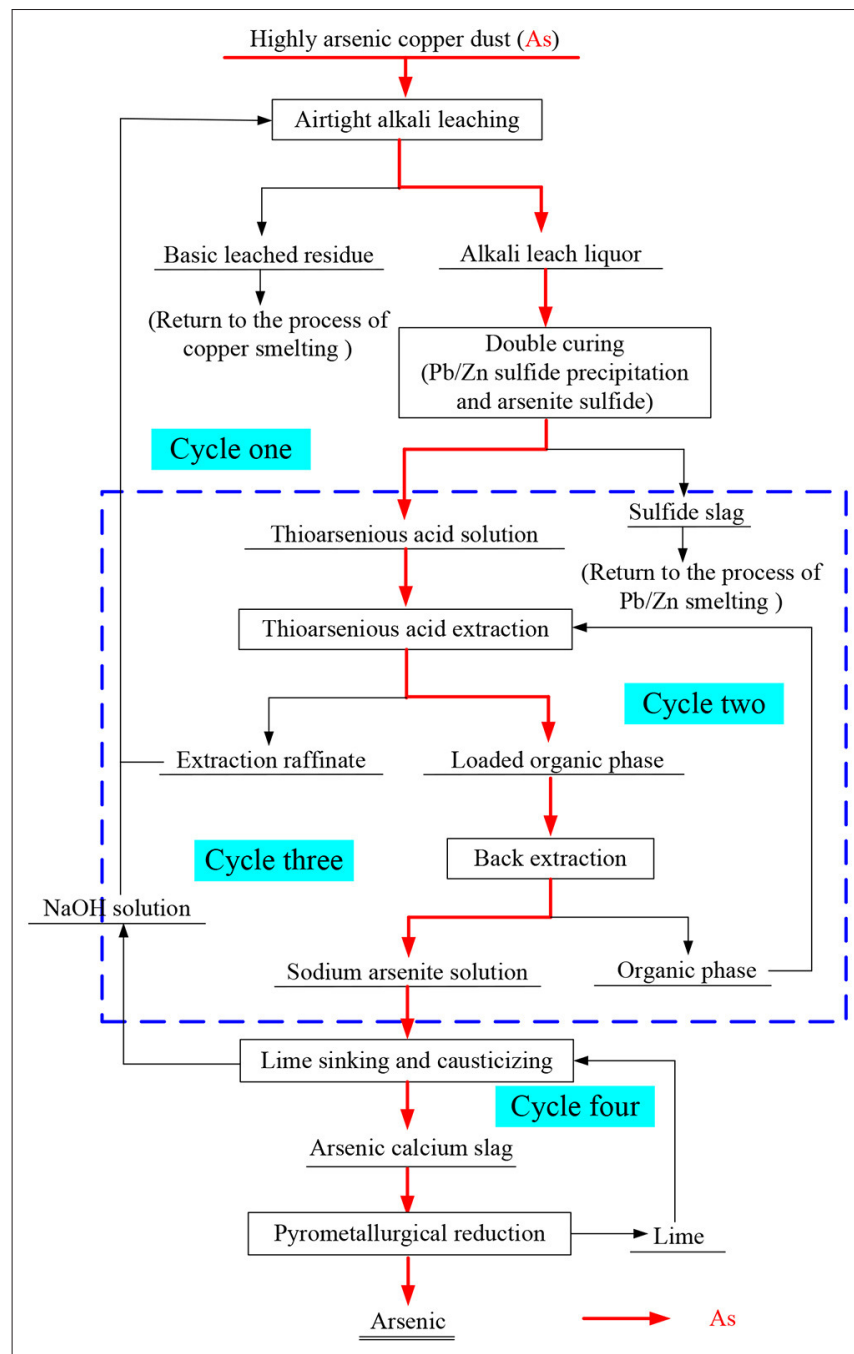

FIGURE 1 | Process flow chart of "closed" alkali leaching double sulfurization coordination solvent extraction arsenic removal lime cascade arsenic deposition carbothermal reduction".

using tri-n-octylmethyl-ammonium chloride (TOMAC) as the extractant and $\mathrm{CO}_{3}^{2-}$ for anion conversion. This study provided solutions for the extraction and separation of arsenic in an alkaline medium and laid the theoretical foundation for the realization of a highly efficient process of arsenic separation, improvement in arsenic resource utilization, and establishment of a comprehensive recovery system of valuable metals.

\section{EXPERIMENTAL}

\section{Materials}

TOMAC was kindly supplied by Shanghai Titan Technology Co., Ltd. All the extractants were used without further purification and dissolved in sulfonated kerosene provided by Nanjing Runchuan Petrochemical Co. Ltd., China at the required concentrations. The thioarsenious acid solutions were prepared by dissolving $\mathrm{NaAsO}_{2}$ and $\mathrm{Na}_{2} \mathrm{~S} \cdot 9 \mathrm{H}_{2} \mathrm{O}$ (Aladdin, Shanghai) in lye

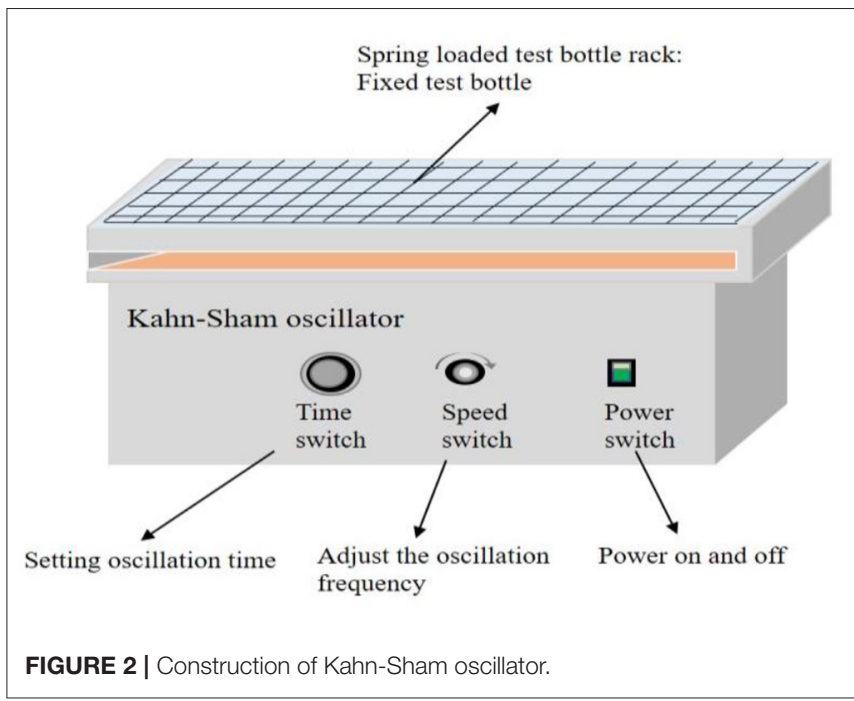

$(\mathrm{NaOH})$ to the required concentration under different conditions of temperature and time. All the other reagents and chemicals used were of analytical reagent grade.

\section{Leaching Experiment TOMAC Transformation From $\mathrm{Cl}^{-}$to $\mathrm{CO}_{3}^{2-}-$ Type Experiment}

After the addition of a certain amount of TOMAC into a pearshaped funnel, $\mathrm{NaHCO}_{3}$ saturated solution was added, $\mathrm{V}_{\mathrm{O}} / \mathrm{V}_{\mathrm{A}}$ $=1 / 1$, and the conditions of water phase are as follows: the concentration of $\mathrm{NaOH}$ is $0.5 \mathrm{~mol} / \mathrm{l}$ and the concentration of $\mathrm{As}^{\mathrm{III}}$ is $9.69 \times 10^{-2} \mathrm{~mol} / \mathrm{l}$. The first extractant transformation was completed after $10 \mathrm{~min}$ of mixing in a Kohn-Sham (KS) oscillator, and the construction is shown in Figure 2. Then, the organic phase and water phase were separated, and the concentration of $\mathrm{Cl}^{-}$in the solution after transformation was analyzed to obtain the anion conversion rate of TOMAC from $\mathrm{Cl}^{-}$to $\mathrm{HCO}_{3}^{-}$type. The second mixed organic phase transformation was conducted using $\mathrm{NaOH}$ solution at a certain concentration by the same experimental procedure as the first. After the second extractant transformation, the concentrations of $\mathrm{CO}_{3}^{2-}$ and $\mathrm{OH}^{-}$in the solution were analyzed again to obtain the anion conversion rate of TOMAC from $\mathrm{HCO}_{3}^{-}$to $\mathrm{CO}_{3}^{2-}$ type.

\section{Extraction of Thioarsenious Acid With $\mathrm{CO}_{3}^{2-}$-Type TOMAC}

$\mathrm{CO}_{3}^{2-}$-type TOMAC and thioarsenious acid solutions were mixed in a pear-shaped separating funnel according to a certain ratio of O/A for a certain period of time in an air bath constant temperature oscillator at a set temperature and then settled for phase separation; then, the concentration of $A s^{\mathrm{III}}$ in the liquid after exchange was analyzed. In this manner, the As ${ }^{\mathrm{III}}$ extraction rate of $\mathrm{CO}_{3}^{2-}$-type TOMAC was obtained.

\section{Loaded Organic Reverse Extraction Experiment}

After a stripping agent was prepared according to a certain concentration, it was placed into a pear-shaped funnel with loaded organic phase at a certain O/A ratio. Then, the phase was 
separated at room temperature after mixing in the KS oscillator for a certain period of time. Then, the $\mathrm{As}{ }^{\mathrm{III}}$ concentration in the solution after conversion was analyzed to obtain its stripping rate in the loaded organic phase.

\section{Analysis Method and Data Processing Detection of As Content in Solution}

The concentration of As is mainly determined using potassium bromate titration in GB/T3884-20128. Using $\mathrm{KBr}$ as the catalyst, arsenic $(\mathrm{V})$ is reduced to a lower valence state in $\mathrm{HCl}$; thereafter, arsenic is separated with $\mathrm{As}_{2} \mathrm{Cl}_{3}$. After the absorption of water by $\mathrm{As}_{2} \mathrm{Cl}_{3}$, sodium $\mathrm{p}$-dimethylaminoazobenzene sulfonate is used as an indicator. Finally, As is titrated with a prepared $\mathrm{KBrO}_{3}$ standard solution. The final concentration of As is expressed by Equation (1),

$$
\beta=V_{2} \times c_{1} \times M_{1} / V_{1} \times 10^{3}
$$

where $\beta$ is the concentration of As ( $\mathrm{mg} / \mathrm{l}), V_{1}$ is the volume of the aqueous phase $(\mathrm{ml}), V_{2}$ is the volume of $\mathrm{KBrO}_{3}$ consumed during the titration $(\mathrm{ml}), c$ is the concentration of the $\mathrm{KBrO}_{3}$ standard solution ( $\mathrm{mol} / \mathrm{l})$, and $\mathrm{M}_{1}$ is the molar mass of $1 / 2$ As $(37.46 \mathrm{~g} / \mathrm{mol})$.

\section{Determination of $\mathrm{Cl}^{-}$Concentration in Solution}

The concentration of $\mathrm{Cl}^{-}$is determined by the molar method, and the analytical procedure is mainly referred to GB/T 15453 2008, with a determination range of $10-120 \mathrm{mg} / \mathrm{l}$. For the $\mathrm{pH}$ value of 5.0-9.5, using $\mathrm{K}_{2} \mathrm{CrO}_{4}$ as the indicator, $\mathrm{AgNO}_{3}$ solution with a known accurate concentration was used to titrate the sample to be determined. $\mathrm{AgNO}_{3}$ reacts with chloride to produce $\mathrm{AgCl}$, and excessive $\mathrm{AgNO}_{3}$ reacts with $\mathrm{K}_{2} \mathrm{CrO}_{4}$ to produce $\mathrm{Ag}_{2} \mathrm{CrO}_{4}$. When a precipitate is produced, the indicator stops dropping. The final concentration of $\mathrm{Cl}^{-}$is expressed by Equation (2),

$$
\rho=V_{4} \times c_{2} \times M_{2} / V_{3} \times 10^{3}
$$

where $\rho$ is the concentration of $\mathrm{Cl}^{-}(\mathrm{mg} / \mathrm{l}), V_{3}$ is the volume of the aqueous phase $(\mathrm{ml}), V_{4}$ is the volume of $\mathrm{AgNO}_{3}$ consumed during the titration $(\mathrm{ml}), c$ is the concentration of the $\mathrm{AgNO}_{3}$ standard solution (mol/l), and $\mathrm{M}_{2}$ is the molar mass of $\mathrm{Cl}^{-}$ $(35.50 \mathrm{~g} / \mathrm{mol})$.

\section{Determination of $\mathrm{CO}_{3}^{2-}$ and $\mathrm{OH}^{-}$Concentrations in Solution}

The concentrations of $\mathrm{CO}_{3}^{2-}$ and $\mathrm{OH}^{-}$were determined using titration. The analysis steps were mainly referred to as DZ/T0064.49-93; the detection range for $\mathrm{CO}_{3}^{2-}$ and $\mathrm{OH}^{-}$ concentration was no less than 10 and $4 \mathrm{mg} / \mathrm{l}$, respectively. The titrant solution of $\mathrm{HCl}$ with a precise known concentration was used; the indicators were phenolphthalein and sodium dimethylaminoazobenzene sulfonic acid solution.

After the addition of an appropriate volume $(V)$ of the feed solution into a conical flask, a few drops of phenolphthalein were added. If the solution turned red, $\mathrm{HCl}$ solution with a precise known concentration was added until the red color in the feed solution faded, and its added amount $\left(V_{5}\right)$ was recorded. Subsequently, three drops of sodium dimethylaminoazobenzene sulfonic acid solution was also added into the conical flask. The continuous addition of $\mathrm{HCl}$ solution with a precise known concentration was performed until the feed solution turned orange, and the amount of $\mathrm{HCl}\left(V_{6}\right)$ added was recorded.

The contents of $\mathrm{CO}_{3}^{2-}$ and $\mathrm{OH}^{-}$are expressed by Equations (3) and (4), respectively:

$$
\begin{array}{r}
C_{1}=\left(V_{5}-V_{6}\right) \times c_{3} \times M_{3} / V_{7} \times 10^{3}, \\
C_{2}=2 V_{6} \times c_{3} \times M_{4} / V_{7} \times 10^{3},
\end{array}
$$

where $C_{1}$ and $C_{2}$ are the concentrations of $\mathrm{OH}^{-}$and $\mathrm{CO}_{3}^{2-}$ (mg/l), respectively, $V_{5}$ and $V_{6}$ are the volumes of $\mathrm{HCl}$ consumed by the first and second titrations $(\mathrm{ml})$, respectively, $V_{7}$ is the volume of the aqueous phase $(\mathrm{ml}), c$ is the concentration of the $\mathrm{HCl}$ standard solution $(\mathrm{mol} / \mathrm{l})$, and $\mathrm{M}_{3}$ and $\mathrm{M}_{4}$ are the molar mass of $\mathrm{OH}^{-}(17.01 \mathrm{~g} / \mathrm{mol})$ and $1 / 2 \mathrm{CO}_{3}^{2-}(30.01$ $\mathrm{g} / \mathrm{mol})$, respectively.

\section{Extraction Rate and Back Extraction Rate of As}

After solvent extraction, the extraction rate of As is calculated using Equation (5),

$$
\eta=\left(C_{3} \times V_{8}-C_{4} \times V_{9}\right) /\left(C_{3} \times V_{8}\right) \times 100 \%
$$

The arsenic-supported organic phase is back-extracted, whereas the back extraction rate of arsenic is calculated by Equation (6):

$$
\sigma=\left(C_{5} \times V_{10}\right) /\left(C_{3} \times V_{8}-C_{4} \times V_{9}\right) \times 100 \%,
$$

where $\eta$ is the extraction ratio of As (\%), $\sigma$ is the stripping ratio of As (\%), $C_{3}$ is the concentration of As in the feed solution $(\mathrm{g} / \mathrm{l})$, $V_{8}$ is the volume of feed solution $(\mathrm{ml}), C_{4}$ is the concentration of As in the raffinate $(\mathrm{g} / \mathrm{l}), V_{9}$ is the volume of raffinate $(\mathrm{ml}), C_{5}$ is the concentration of As in the strip liquor $(\mathrm{g} / \mathrm{l})$, and $V_{10}$ is the volume of strip liquor $(\mathrm{ml})$.

\section{RESULTS AND DISCUSSION}

\section{The Transformation of TOMAC}

\section{$\mathrm{CO}_{3}^{2-}$ Transformation Mechanism of TOMAC}

According to the literature (Wu et al., 2017; Buev et al., 2018), the more lipophilic anions are more likely to react with the quaternary ammonium cations and enter the organic phase. The order of association of quaternary ammonium cations with each anion is roughly as follows:

$$
\begin{aligned}
\mathrm{ClO}_{4}^{-} & >\mathrm{I}^{-}>>\mathrm{ClO}_{3}^{-}>\mathrm{Cl}^{-}>\mathrm{HSO}_{4}^{-}>\mathrm{HCO}_{3}^{-}>\mathrm{SO}_{4}^{2-} \\
& >\mathrm{OH}^{-}>\mathrm{CO}_{3}^{2-}>\mathrm{S}^{2-}>\mathrm{AsO}_{4}^{3-}>\mathrm{SiO}_{3}^{2-}
\end{aligned}
$$

From the above, the association ability of $\mathrm{Cl}^{-}$to quaternary ammonium salt cation is evidently relatively strong, whereas that 
of arsenic anion is relatively weak, which is the main reason for the inhibition of arsenic extraction. A larger anion radius corresponds to a smaller charge, and a lower degree of hydration of the aqueous solution corresponds to a greater advantage in extraction (Suflet et al., 2015; Chauhan and Kaur, 2017). It can be inferred that the association ability of $\mathrm{HAsOS}_{2}^{2-}$ is between $\mathrm{CO}_{3}^{2-}$ and $\mathrm{AsO}_{4}^{3-}$, and the extraction ability of arsenic may be improved if the $\mathrm{Cl}^{-}$quaternary ammonium salt is transformed into the $\mathrm{CO}_{3}^{2-}$ type. However, the direct transformation process may not be easy to perform, because the strong association anion is easy to exchange with the weak association anion; otherwise, it is very difficult.

The experimental results of direct transformation of TOMAC by $8 \% \mathrm{Na}_{2} \mathrm{CO}_{3}$ showed that under the conditions of $30 \%$ TOMAC $+15 \%$ sec-octyl alcohol $+55 \%$ sulfonated kerosene, $\mathrm{V}_{\mathrm{O}} / \mathrm{V}_{\mathrm{A}}=1 / 1$, the compositions of water phase are $0.5 \mathrm{~mol} / \mathrm{l}$ $\mathrm{NaOH}$, the concentration of $\mathrm{As}^{\mathrm{III}}$ is $9.69 \times 10^{-2} \mathrm{~mol} / \mathrm{l}$, and as the transformation times range from 1 to 5 , the extraction rate of $\mathrm{As}^{\mathrm{III}}$ is from 47.3 to $63.7 \%$. The extraction rate hardly increased with the transformation time increase. In view of the difficulty of the direct conversion from $\mathrm{Cl}^{-}$-type TOMAC to $\mathrm{CO}_{3}^{2-}$-type TOMAC, this study also considered a step-by-step conversion method. Because the associative ability of $\mathrm{HCO}_{3}^{-}$is clearly stronger than that of $\mathrm{CO}_{3}^{2-}$ and weaker than that of $\mathrm{Cl}^{-}$, based on the principle of concentration gradient equilibrium, the $\mathrm{Cl}^{-}$-type quaternary ammonium salt is first converted into $\mathrm{HCO}_{3}^{-}$-type by a high-concentration $\mathrm{HCO}_{3}^{-}$solution. Then, the final conversion of $\mathrm{CO}_{3}^{2-}$ is achieved by alkaline washing.

The conversion process of $\mathrm{Cl}^{-}$- to $\mathrm{HCO}_{3}^{-}$-type TOMAC can be expressed by the following Equation (7):

$$
\mathrm{R}_{4} \mathrm{NCl}+\mathrm{HCO}_{3}^{-} \rightarrow \mathrm{R}_{4} \mathrm{NHCO}_{3}+\mathrm{Cl}^{-} .
$$

The intermediate product $\mathrm{HCO}_{3}^{-}$-type TOMAC is subjected to alkaline washing, and the reaction expressed in Equation (8) is

$$
2 \mathrm{R}_{4} \mathrm{NHCO}_{3}+2 \mathrm{OH}^{-} \rightarrow\left(\mathrm{R}_{4} \mathrm{~N}\right)_{2} \mathrm{CO}_{3}+\mathrm{CO}_{3}^{2-}+2 \mathrm{H}_{2} \mathrm{O} .
$$

\section{$\mathrm{CO}_{3}^{2-}$ Transformation Process of TOMAC}

The experiment was conducted using a saturated $\mathrm{NaHCO}_{3}$ aqueous solution as a transition agent, and the effect of the number of treatments with saturated $\mathrm{NaHCO}_{3}$ solution on the conversion of TOMAC from $\mathrm{Cl}^{-}$- to $\mathrm{HCO}_{3}^{-}$-type was investigated. The experimental results are shown in Figure 3.

As shown in Figure 3, the extraction rate of As ${ }^{\mathrm{III}}$ from TOMAC significantly increases after the saturated $\mathrm{NaHCO}_{3}$ treatment, from 16.3 to $32.8 \%$ after one saturated $\mathrm{NaHCO}_{3}$ treatment. This shows that improving the extraction capacity of $\mathrm{As}^{\mathrm{III}}$ is feasible through the transformation of TOMAC. Further, Figure 3 shows that with increasing number of times of contact between organic phase and saturated $\mathrm{NaHCO}_{3}$ solution, the concentration of $\mathrm{Cl}^{-}$in the solution after conversion successively decreases, indicating that the transformation efficiency is constantly improving. Moreover, as the concentration of $\mathrm{Cl}^{-}$in the solution after conversion decreases and gradually reaches

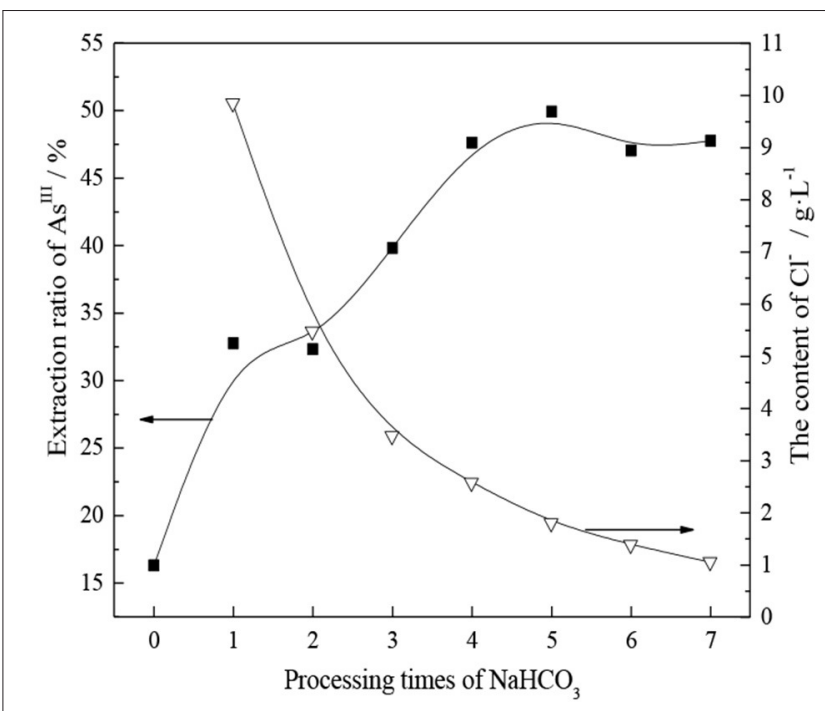

FIGURE 3 | Relationship between the extraction rate of As ${ }^{\text {III }}$ and the number of treatments with saturated $\mathrm{NaHCO}_{3}$.

equilibrium, the extraction rate of $\mathrm{As}^{\mathrm{III}}$ after the extractant transformation continues to increase to $47.5 \%$, until a significant change is no longer observed. In summary, after treating the organic phase with saturated $\mathrm{NaHCO}_{3}$ five times, the $\mathrm{Cl}^{-}$-type quaternary ammonium salt can be effectively converted into $\mathrm{HCO}_{3}^{-}$-type quaternary ammonium salt.

From section $\mathrm{CO}_{3}^{2-}$ Transformation Mechanism of TOMAC, TOMAC of $\mathrm{HCO}_{3}^{-}$type can be further transformed into $\mathrm{CO}_{3}^{2-}$ type by alkali washing. However, in the process of alkali washing, if the concentration of $\mathrm{NaOH}$ is too high, TOMAC may be transformed into $\mathrm{R}_{4} \mathrm{NOH}$, with poor stability. If the concentration of $\mathrm{NaOH}$ is too low, the number of alkali washings may need to increase, which affects the transformation efficiency (Weisshaar et al., 2012). Therefore, the effects of $\mathrm{NaOH}$ concentration and the number of alkali washings on the further conversion of $\mathrm{HCO}_{3}^{-}$-type quaternary ammonium salt and the extraction rate of $\mathrm{As}^{\mathrm{III}}$ were investigated, respectively, and the experimental results are shown in Figure 4.

As shown in Figure 4, with the $\mathrm{NaOH}$ concentration range of $0.5-1.0 \mathrm{~mol} / \mathrm{l}$ in the wash solution, the treatment has little effect on the As ${ }^{\mathrm{III}}$ extraction rate; however, the As ${ }^{\mathrm{III}}$ extraction rate increases more significantly with an increase in the number of treatments. For an $\mathrm{NaOH}$ concentration of $1.5 \mathrm{~mol} / \mathrm{l}$, the extraction rate of $\mathrm{As}^{\mathrm{III}}$ increases with an increase in the number of treatments. The extraction efficiency of As ${ }^{\mathrm{III}}$ increases with the number of alkali washings owing to the transformation of TOMAC from $\mathrm{HCO}_{3}^{-}$to $\mathrm{CO}_{3}^{2-}$ type.

The effects of $\mathrm{NaOH}$ concentration and number of alkaline washings on the As ${ }^{\mathrm{II}}$ extraction rate were comprehensively analyzed, and results are shown in Figure 5. Under different alkali concentration conditions, with an increase in the number of alkali washings, the pattern of successive increases of As ${ }^{\mathrm{III}}$ extraction rate remains basically the same. With an increase in 


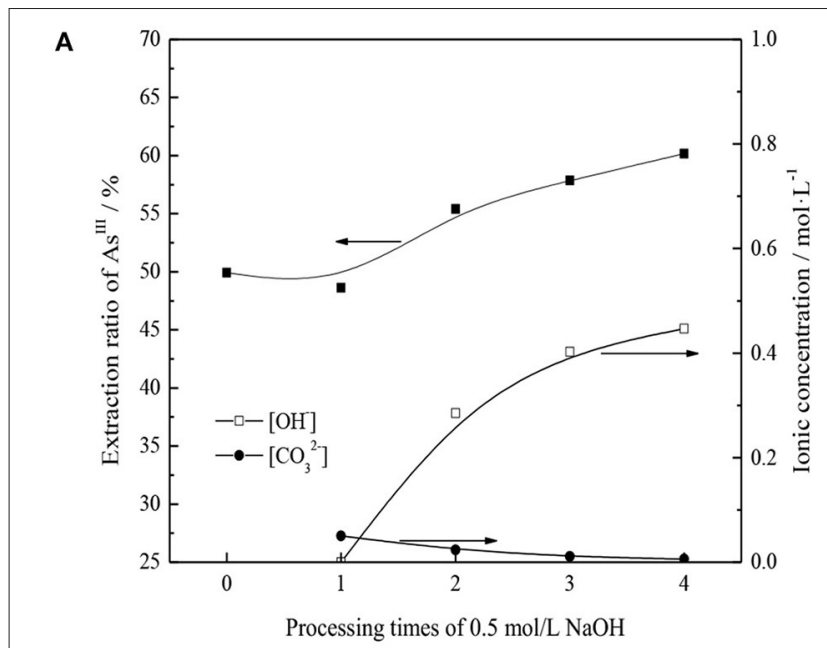

\section{B}

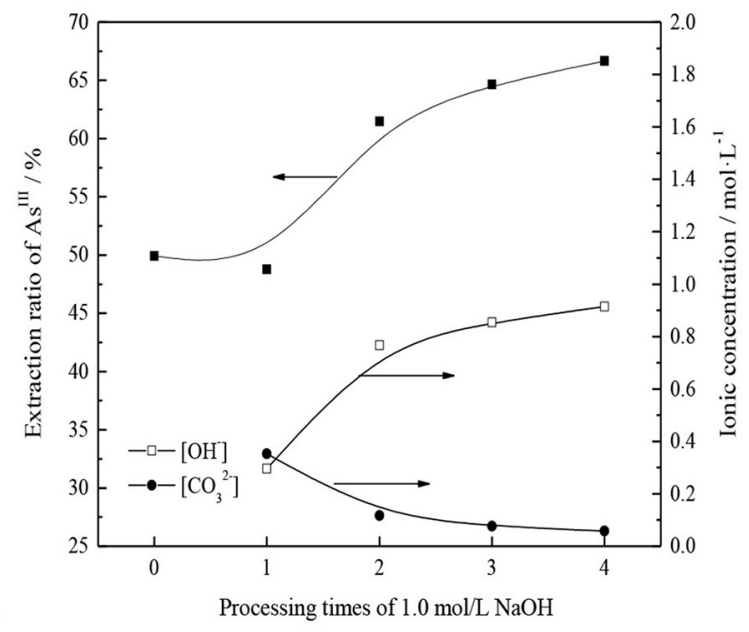

C

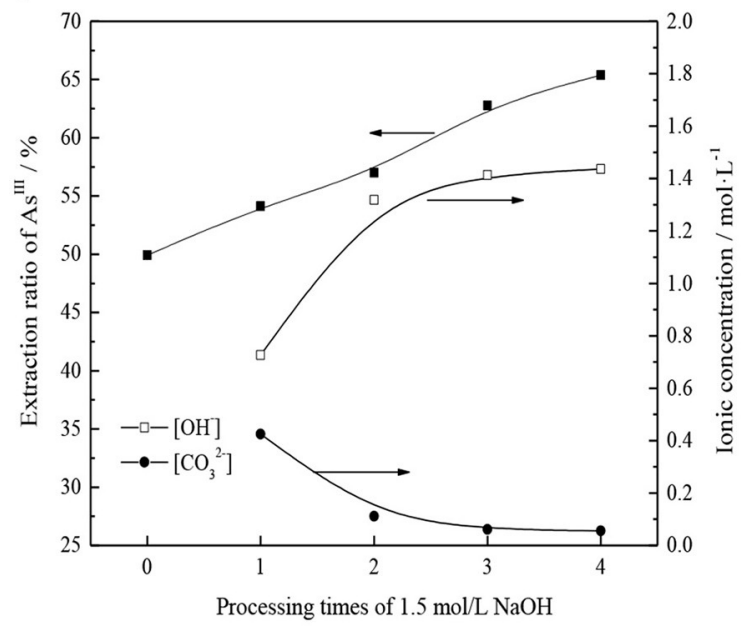

FIGURE 4 | (A) NaOH concentration is $0.5 \mathrm{~mol} / \mathrm{L}$ and treatment times on As ${ }^{\text {III }}$ extraction rate and concentration of ions in alkaline washing solution. (B) $\mathrm{NaOH}$ concentration is $1.0 \mathrm{~mol} / \mathrm{L}$ and treatment times on $\mathrm{As}^{\mathrm{III}}$ extraction rate and concentration of ions in alkaline washing solution. (C) $\mathrm{NaOH}$

concentration is $1.5 \mathrm{~mol} / \mathrm{L}$ and treatment times on As ${ }^{\mathrm{III}}$ extraction rate and concentration of ions in alkaline washing solution.

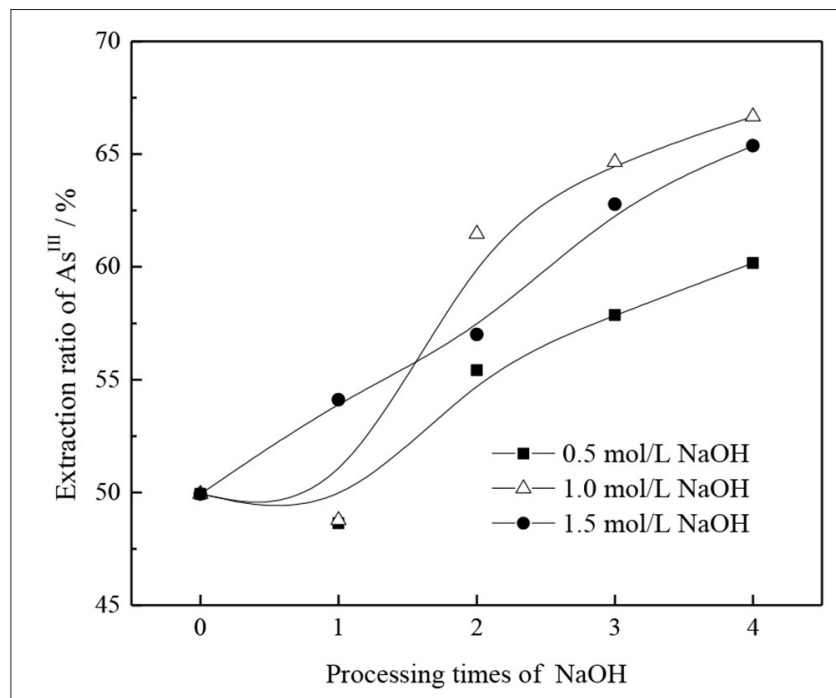

FIGURE 5 | Effect of alkaline washing times on As ${ }^{\text {III }}$ extraction rate under different $\mathrm{NaOH}$ concentrations.

the $\mathrm{NaOH}$ concentration from 0.5 to $1.0 \mathrm{~mol} / \mathrm{l}$, the promotion effect of alkaline washing on As ${ }^{\mathrm{III}}$ extraction can be clearly demonstrated only when the number of alkaline washings is more than two. When the $\mathrm{NaOH}$ concentration is further increased to $1.5 \mathrm{~mol} / \mathrm{l}$ and the number of alkaline washings is more than two, the extraction rate of As ${ }^{\mathrm{III}}$ is significantly better than that obtained at $0.5 \mathrm{~mol} / \mathrm{l} \mathrm{NaOH}$ but lower than that obtained at 1.0 $\mathrm{mol} / \mathrm{l} \mathrm{NaOH}$. This may be due to the fact that with an increase in alkalinity, in addition to the neutralization reaction of $\mathrm{HCO}_{3}^{-}$ group in organic phase, excessive $\mathrm{OH}^{-}$replaces the generated $\mathrm{CO}_{3}^{2-}$ groups. Owing to the relatively stronger $\mathrm{OH}^{-}$association ability, the As ${ }^{\mathrm{III}}$ extraction capacity is reduced.

Based on the above, the extraction rate of $\mathrm{As}^{\mathrm{III}}$, the amount of $\mathrm{NaOH}$, and the conversion efficiency are comprehensively considered to convert TOMAC from $\mathrm{HCO}_{3}^{-}$to $\mathrm{CO}_{3}^{2-}$ type effectively; $1.0 \mathrm{~mol} / \mathrm{l} \mathrm{NaOH}$ solution was selected for washing three times.

It can be known from the above experimental results and analysis that $\mathrm{CO}_{3}^{2-}$-type TOMAC has a significant effect on the extraction rate of As ${ }^{\mathrm{III}}$ in alkaline solution. The transformation process of TOMAC is accomplished in two steps, $\mathrm{Cl}^{-}$to $\mathrm{HCO}_{3}^{-}$type and $\mathrm{HCO}_{3}^{-}$to $\mathrm{CO}_{3}^{2-}$ type; how to improve the transformation rate of these two processes is the critical process.

\section{Infrared Spectrum Analysis Before and After $\mathrm{CO}_{3}^{2-}$ Transformation of TOMAC}

TOMAC before and after transformation $\left(\mathrm{CO}_{3}^{2-}\right.$ type $)$ is detected and analyzed, respectively, by Fourier transform infrared spectroscopy, and the obtained infrared spectrum is shown in Figure 6.

Figure 6 represents the FTIR spectra of TOMAC before and after the transformation. The peaks at $\sim 2,963, \sim 2,926$, and $\sim 2,856 \mathrm{~cm}^{-1}$ can be assigned to the $-\mathrm{CH}_{2}$ - stretching. 


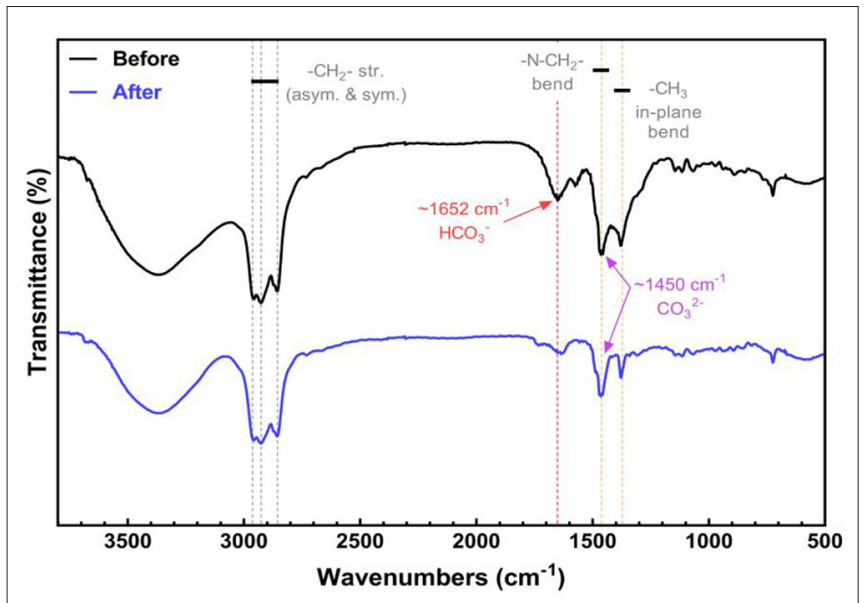

FIGURE 6 | Infrared spectra of TOMAC before and after transformation.

The characteristic vibration bands at $\sim 1,462$ and $\sim 1,372 \mathrm{~cm}^{-1}$ represent the $\mathrm{N}-\mathrm{CH}_{2}$ - bending and in-plane bending of $\mathrm{CH}_{3}$, respectively. The characteristic IR band of $\mathrm{HCO}_{3}^{-}$at $\sim 1,652 \mathrm{~cm}^{-1}$ can be found in the spectrum of TOMAC before the transformation. However, the characteristic peak of $\mathrm{HCO}_{3}^{-}$disappears after the $\mathrm{NaOH}$ treatment, revealing the transformation from $\mathrm{HCO}_{3}^{-}$to $\mathrm{CO}_{3}^{2-}$. It should be noted that the characteristic peak of $\mathrm{CO}_{3}^{2-}$ locates at $\sim 1,450 \mathrm{~cm}^{-1}$, which

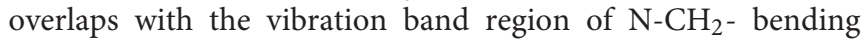
(Larkin, 2011). Thus, it is difficult to distinguish the two vibration bands from the FTIR spectra.

\section{Extraction of Thioarsenious Acid by $\mathrm{CO}_{3}^{2-}$-Type TOMAC \\ Extraction Mechanism of $\mathrm{CO}_{3}^{2-}$-Type TOMAC}

The extraction capacity of thioarsenious acid in the $\mathrm{CO}_{3}^{2-}$ type TOMAC organic phase was determined by the continuous saturation method (Zhu, 2005).

First, the organic phase of 30\% TOMAC $+15 \%$ sec-octyl alcohol $+55 \%$ sulfonated kerosene was transformed into $\mathrm{CO}_{3}^{2-}$, and the aqueous solution containing arsenic was presulfurized. After the transformation, the organic phase was repeatedly contacted with fresh water phase under the condition of phase ratio $\mathrm{O} / \mathrm{A}=1 / 1$ and vibrated and mixed for $10 \mathrm{~min}$ each time. The concentration of $A s^{\mathrm{III}}$ in the raffinate was analyzed after each extraction reached equilibrium; then, the content of $\mathrm{As}{ }^{\mathrm{III}}$ in the organic phase was calculated by subtraction method and accumulated step by step. The concentration of $\mathrm{As}{ }^{\mathrm{III}}$ in the raffinate is basically the same as that in the aqueous solution before extraction, until no significant change is observed in the As ${ }^{\mathrm{III}}$ concentration in the loaded organic phase. The extraction isotherms were plotted based on the concentration relationship between $\mathrm{As}^{\mathrm{III}}$ in the loaded organic phase and that in the equilibrium aqueous phase, as shown in Figure 7.

In Figure 7, the $\mathrm{As}^{\mathrm{III}}$ content enriched in the $\mathrm{CO}_{3}^{2-}$-type TOMAC increases with increasing number of times of contact

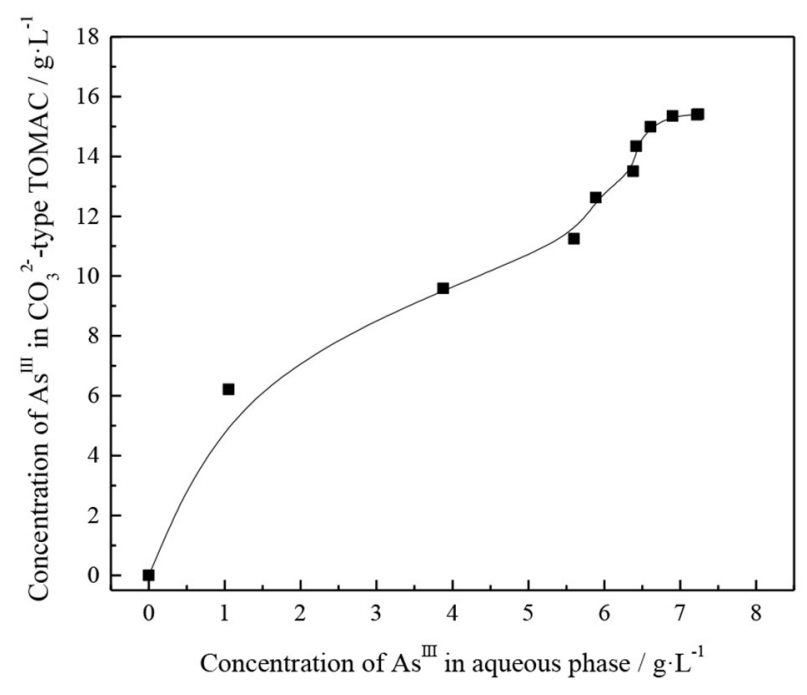

FIGURE 7 | Isotherm of thioarsenite extraction.

between the $\mathrm{CO}_{3}^{2-}$-type TOMAC and the feed liquid. The content of $\mathrm{As}^{\mathrm{III}}$ in raffinate was almost the same as that in the feed after $\mathrm{CO}_{3}^{2-}$-type TOMAC was contacted with the feed nine times; thus, the organic phase can be considered to have been saturated, and the saturation capacity of $\mathrm{CO}_{3}^{2-}$-type TOMAC for extracting thioarsenious acid was $15.41 \mathrm{G} / 1(0.21 \mathrm{~mol} / \mathrm{l})$. When $\mathrm{CO}_{3}^{2-}$ type TOMAC is used to extract thioarsenious acid, the following reactions occur:

$$
\begin{aligned}
\left(R_{4} N\right)_{2} \mathrm{CO}_{3}+\mathrm{HAsOS}_{2}^{2-} & \rightarrow\left(R_{4} \mathrm{~N}\right)_{2} \mathrm{HAsOS}_{2}+\mathrm{CO}_{3}^{2-} . \\
\left(R_{4} \mathrm{~N}\right)_{2} \mathrm{CO}_{3}+\mathrm{HAsO}_{2} \mathrm{~S}^{2-} & \rightarrow\left(R_{4} \mathrm{~N}\right)_{2} \mathrm{HAsO}_{2} \mathrm{~S}+\mathrm{CO}_{3}^{2-} .
\end{aligned}
$$

\section{Effect of Volume Fraction of $\mathrm{CO}_{3}^{2-}$-Type TOMAC on As ${ }^{\text {III }}$ Extraction}

Under the conditions of $15 \%$ secondary octanol concentration, $\mathrm{V}_{\mathrm{O}} / \mathrm{V}_{\mathrm{A}}=1 / 1$, and normal temperature, oil, and water were mixed and shaken for $10 \mathrm{~min}$. Then, the effects of the volume fraction of $\mathrm{CO}_{3}^{2-}$-type TOMAC on the single-stage extraction rate of $\mathrm{As}^{\mathrm{III}}$ and oil-water phase separation were investigated, and the experimental results are shown in Figure 8.

As seen from Figure 8, for a TOMAC concentration within $30 \%$, the $\mathrm{As}^{\mathrm{III}}$ extraction rate has a significant increase trend with an increase in the volume fraction of $\mathrm{CO}_{3}^{2-}$-type TOMAC. As the volume fraction of $\mathrm{CO}_{3}^{2-}$-type TOMAC increases from 10 to $30 \%$, the extraction yield of $A s^{\mathrm{III}}$ increases from 68.3 to $85.5 \%$ and further increases to $50 \%$ with the volume fraction of the $\mathrm{CO}_{3}^{2-}$ type TOMAC. The extraction rate of As ${ }^{\mathrm{III}}$ slightly increases to $86.3 \%$, and the volume fraction has no significant effect on the extraction rate. As is further apparent from Figure 8, the oilwater phase time increases with the extractant concentration. When the volume fraction of $\mathrm{CO}_{3}^{2-}$-type TOMAC reached $50 \%$, the time of the oil-water phase was prolonged to nearly $9 \mathrm{~min}$, which was unfavorable to the extraction operation. 


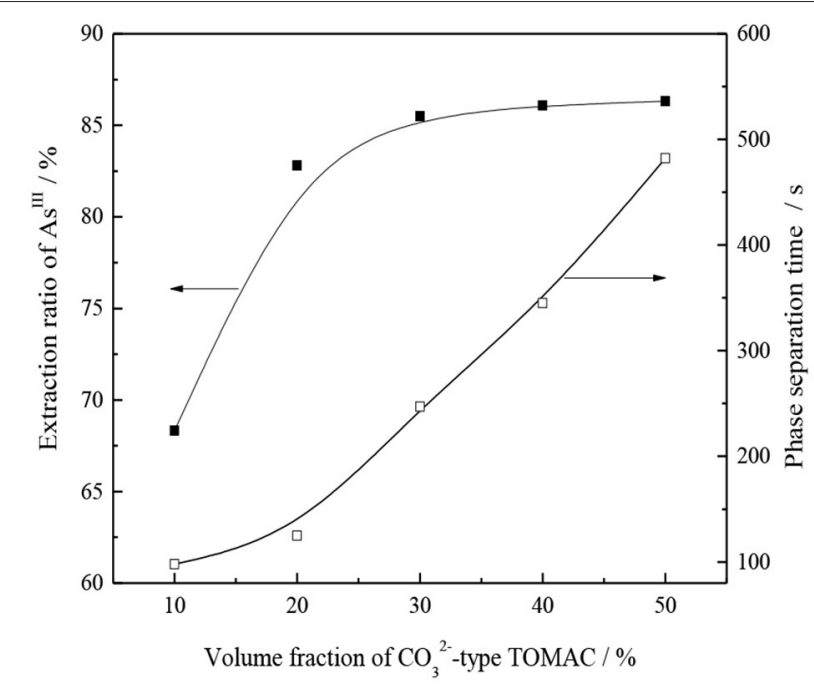

FIGURE 8 | Effect of volume fraction of $\mathrm{CO}_{3}^{2-}$-type TOMAC on As'll extraction and phase separation.

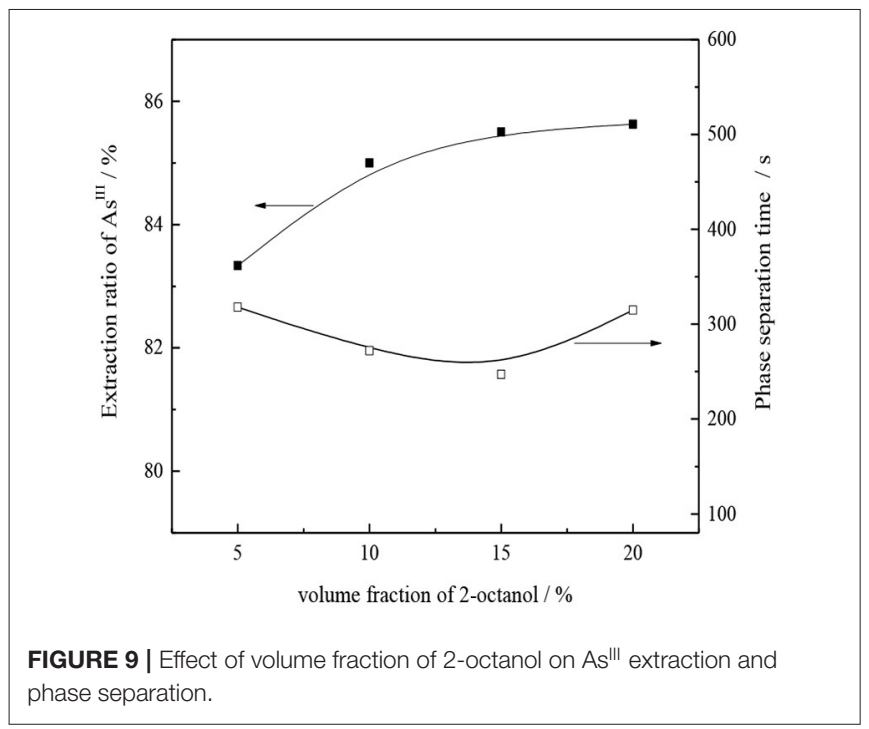

The volume fraction of $\mathrm{CO}_{3}^{2-}$-type TOMAC was $30 \%$, the extraction yield of $\mathrm{As}{ }^{\mathrm{III}}$ was $85.5 \%$, and the time of the phase separation was $\sim 4 \mathrm{~min}$.

\section{Effect of Volume Fraction of 2-octanol}

The use of DL-2-octanol as the polarity improver is conducive to the depolymerization of $\mathrm{CO}_{3}^{2-}$-type TOMAC (Uslu, 2008), thereby increasing the effective ion concentration of the extractant and improving the extraction effect. Under the conditions of $30 \% \mathrm{CO}_{3}^{2-}$-type TOMAC (volume fraction), $\mathrm{V}_{\mathrm{O}} / \mathrm{V}_{\mathrm{A}}=1 / 1$, and room temperature, the effect of DL-2-octanol concentration on the As ${ }^{\mathrm{II}}$ single-stage extraction rate and oilwater phase separation was investigated by oscillating the oilwater mixture for $10 \mathrm{~min}$, and results are shown in Figure 9.

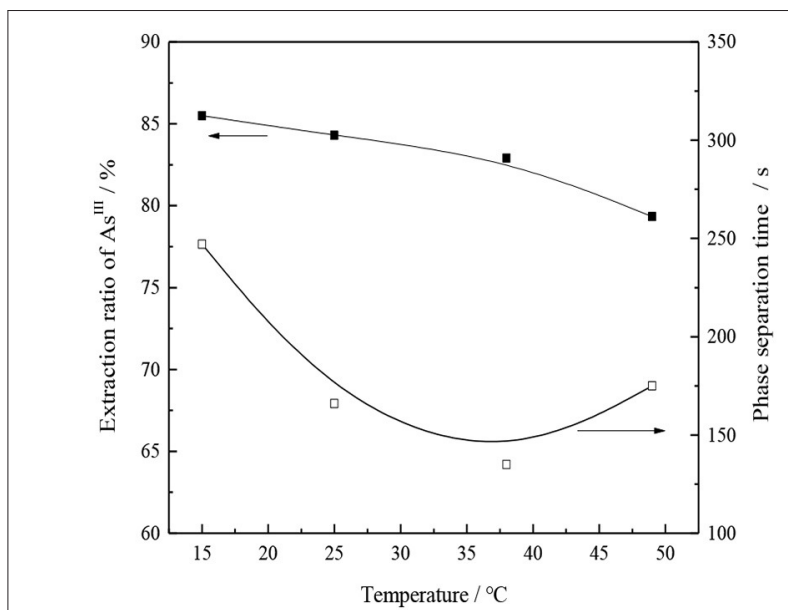

FIGURE 10 | Effect of temperature on As ${ }^{\text {III }}$ extraction and phase separation.

As seen from Figure 9, as the secondary octanol concentration increases from 5 to $15 \%$, the $\mathrm{As}{ }^{\mathrm{III}}$ extraction yield slightly increases from 83.3 to $85.5 \%$. With the further increase in the amount of 2-octanol, the extraction of As ${ }^{\mathrm{III}}$ shows no significant improvement; however, the loss of organic phase in water may increase. Therefore, a suitable concentration of 2-octanol is $15 \%$, for an oil-water phase time of $\sim 4 \mathrm{~min}$, in which the phase separation is relatively fast and clear.

\section{Effect of Extraction Temperature}

The transfer rate between the oil and water phases can be affected by the change in temperature, which may also affect the equilibrium of extraction reaction. Under the condition of $30 \%$ $\mathrm{CO}_{3}^{2-}$-type TOMAC $+15 \%$ secondary octanol $+55 \%$ sulfonated kerosene and $\mathrm{V}_{\mathrm{O}} / \mathrm{V}_{\mathrm{A}}=1 / 1$, the oil and water were mixed and oscillated for $10 \mathrm{~min}$, and the effect of temperature change on the single-stage extraction rate of $\mathrm{As}{ }^{\mathrm{III}}$ was investigated while the oil and water phases were carried out at room temperature. The experimental results are shown in Figure $\mathbf{1 0 .}$

With the increase in the temperature, the viscosity of the organic phase normally decreases, which facilitates the extraction process; however, for the TOMAC extraction of As ${ }^{\mathrm{III}}$, the As ${ }^{\mathrm{III}}$ extraction rate does not increase but rather decreases with an increase in the extraction temperature (see Figure 10).

According to van't Hoff equation of the chemical reaction (Richards, 1926; Deiters, 2012),

$$
\frac{\mathrm{d} \ln K}{d T}=\frac{\Delta H}{R T^{2}},
$$

where $K$ is the equilibrium constant, $T$ is the absolute temperature $\left({ }^{\circ} \mathrm{C}\right), \Delta H$ is the enthalpy change $(\mathrm{kJ} / \mathrm{mol})$, and $R$ is the universal gas constant $\left(8.314 \mathrm{~J} \cdot \mathrm{mol}^{-1} \cdot \mathrm{K}^{-1}\right)$.

As $\Delta H$ does not vary significantly with temperature and the temperature range discussed in this experiment is narrow, $\Delta H$ can be assumed to have a certain value, independent of 
TABLE 1 | Parameters such as extraction rate and partition ratio at different temperatures.

\begin{tabular}{lcccc}
\hline Temperature $\left({ }^{\circ} \mathbf{C}\right)$ & Extraction rate (\%) & Distribute ratio $\boldsymbol{D}$ & $\ln \boldsymbol{D}$ & $\mathbf{1 / T}\left(\mathbf{K}^{-1}\right)$ \\
\hline 15 & 85.5 & 5.91 & 1.78 & 0.00347 \\
25 & 84.30 & 5.37 & 1.68 & 0.00336 \\
38 & 82.09 & 4.58 & 1.52 & 0.00322 \\
49 & 79.34 & 3.84 & 1.35 & 0.00311
\end{tabular}

temperature. Integrating Equation (11), we get

$$
\ln K=-\frac{\Delta H}{R T}+C(\text { Cisconstant })
$$

Equation (11) shows that the equilibrium constant of the reaction is linear with $1 / T$.

As most of the thioarsenious acid in the system exists in the form of $\mathrm{HAsOS}_{2}^{2-}$, to simplify the calculation, only the reaction in Equation (9) is considered, from which the equilibrium constant $K_{e x}$ is derived,

$$
K_{e x}=\frac{\left[\left(\mathrm{R}_{4} \mathrm{~N}\right)_{2} \mathrm{HAsOS}_{2}\right]\left[\mathrm{CO}_{3}^{2-}\right]}{\left[\left(\mathrm{R}_{4} \mathrm{~N}\right)_{2} \mathrm{CO}_{3}\right]\left[\mathrm{HAsOS}_{2}^{2-}\right]}
$$

According to the distribution ratio formula,

$$
D=\frac{\left[\left(R_{4} N\right)_{2} \mathrm{HAsOS}_{2}\right]}{\left[\mathrm{HAsOS}_{2}{ }^{2-}\right]} \text {. }
$$

From Equations (12) and (13), the relationship between the reaction equilibrium constant and distribution ratio can be obtained

$$
K_{e x}=\frac{D\left[\mathrm{CO}_{3}{ }^{2-}\right]}{\left[\left(\mathrm{R}_{4} \mathrm{~N}\right)_{2} \mathrm{CO}_{3}{ }^{2-}\right]} .
$$

Taking the logarithm of both sides at the same time yields

$$
\ln K_{e x}=\ln D+\ln \left[C_{3}^{2-}\right]-\ln \left[\left(R_{4} N\right)_{2} C O_{3}\right]^{2} .
$$

As the concentration of the extractant TOMAC is constant at $30 \%$ and the concentration of the $\mathrm{CO}_{3}^{2-}$ ion changes slightly, the last two terms in Equation (15) can be assumed to be constants for the sake of simplification. Consequently,

$$
\ln D=-\frac{\Delta H}{R T}+C^{\prime} \quad\left(C^{\prime} \text { isconstant }\right)
$$

Based on the experimental data, the extraction rate, distribution ratio, and other parameters obtained under different temperature conditions are calculated, and the results are shown in Table 1.

Plot and fit $1 / T$ and $\ln D$ in Table 1 , and the result is shown in

\section{Figure 11.}

As can be seen from Figure 11, 1/T and $\ln D$ have a linear relationship, and the fitted equation is

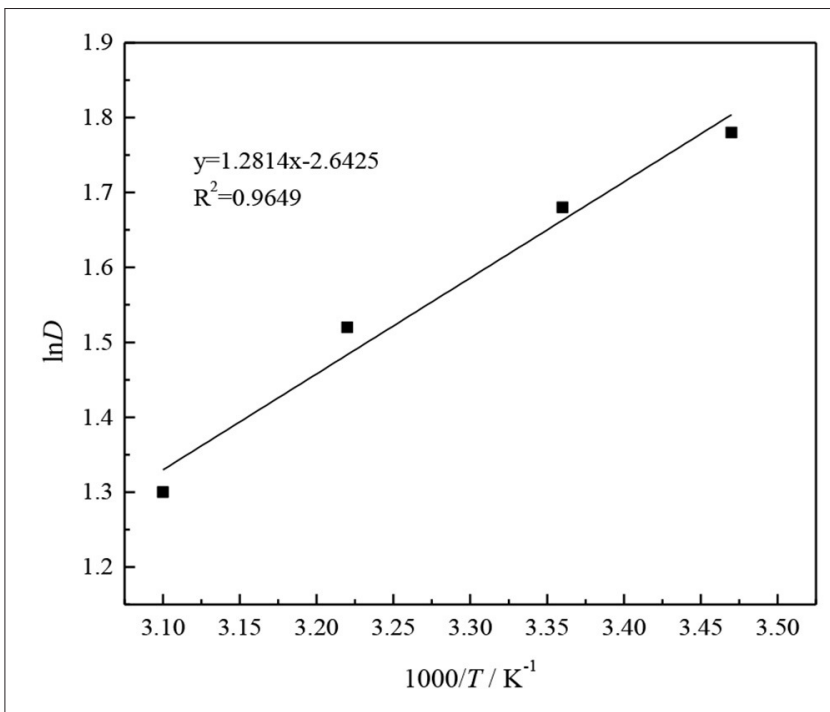

FIGURE 11 | Relationship between $1 / T$ and $\ln D$ and fitting results.

$$
y=1.2814 x-2.6425\left(R^{2}=0.9649\right) .
$$

From Equation (17), we can see that the slope of the fitted straight line is 1.2814 .

$$
\Delta H=-R \times 1.2814=-10.6536 \mathrm{~kJ} / \mathrm{mol} .
$$

From the calculation, it is evident that the process of extracting thioarsenious acid with $\mathrm{CO}_{3}^{2-}$-type TOMAC is an exothermic reaction, and when the extraction temperature increases, the equilibrium of the extraction reaction proceeds in the reverse direction, which is not conducive to the extraction of As ${ }^{\mathrm{III}}$.

As seen from Figure 10, as the extraction temperature increases from 15 to $50^{\circ} \mathrm{C}$, the extraction ratio of $\mathrm{As}^{\mathrm{III}}$ decreases from 85.5 to $79.33 \%$, which indicates that the extraction of thioarsenious acid by $\mathrm{CO}_{3}^{2-}$-type TOMAC is an exothermic reaction. Although the temperature increase speeds up the phase separation, it is still not conducive to the extraction of As ${ }^{\text {III }}$; thus, with comprehensive consideration, the extraction process should be conducted at room temperature.

\section{Effect of Extraction Time}

Under the conditions of organic phase composition $30 \% \mathrm{CO}_{3}^{2-}$ type TOMAC $+15 \%$ secondary octanol $+55 \%$ sulfonated kerosene, $\mathrm{V}_{\mathrm{O}} / \mathrm{V}_{\mathrm{A}}=1 / 1$, and normal temperature, the effects of the oil-water mixed extraction time on the single-stage extraction rate of $\mathrm{As}^{\mathrm{III}}$ and oil-water phase separation are investigated, and the experimental results are shown in Figure 12.

As shown in Figure 12, the extraction of $\mathrm{As}^{\mathrm{III}}$ can reach equilibrium in $\sim 3 \mathrm{~min}$, extraction rate of $\mathrm{As}^{\mathrm{III}}$ reaches $85.2 \%$, and extraction rate of $\mathrm{As}{ }^{\mathrm{III}}$ does not change significantly with the further extension of the extraction time, which indicates that the extraction process is relatively fast and the phase separation 


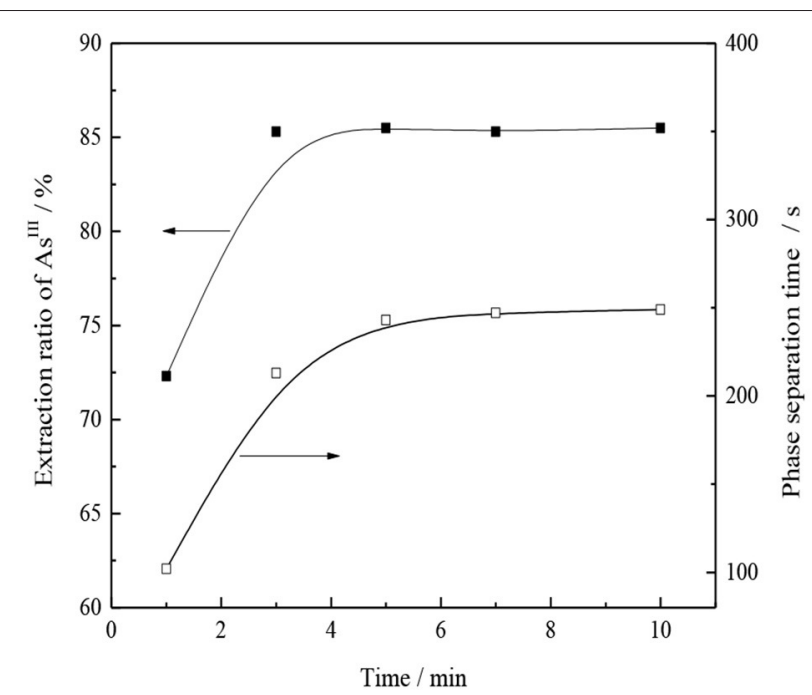

FIGURE 12 | Effect of extraction time on As ${ }^{\text {III }}$ extraction and phase separation.

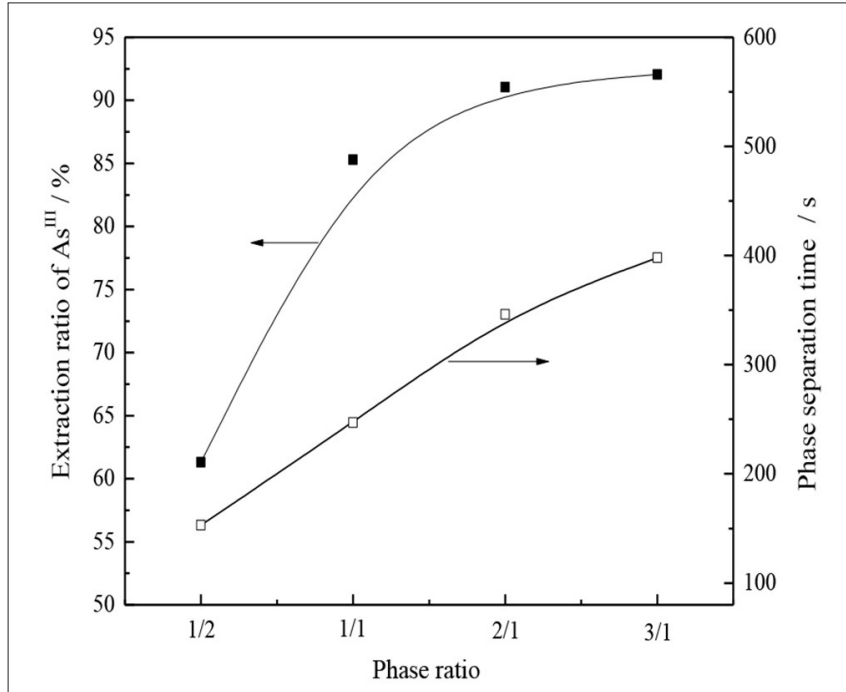

FIGURE 13 | Effect of phase ratio on As ${ }^{\text {III }}$ extraction and phase separation.

is also fast, i.e., $\sim 4 \mathrm{~min}$. To ensure the full mixing of oil and water, an extraction time of 5 min was selected under the experimental conditions.

\section{Effect of Phase Ratio}

Under the condition of organic phase composition $30 \% \mathrm{CO}_{3}^{2-}$ type TOMAC $+15 \%$ secondary octanol $+55 \%$ sulfonated kerosene and extraction for $5 \mathrm{~min}$ at room temperature, the effect of the oil-water contact ratio on the single-stage extraction rate and phase separation of $\mathrm{As}^{\mathrm{III}}$ was investigated, and the experimental results are shown in Figure 13.

As seen from Figure 13, the extraction rate of $\mathrm{As}^{\mathrm{III}}$ and the phase separation time increase with an increase in the phase ratio. When the $\mathrm{V}_{\mathrm{O}} / \mathrm{V}_{\mathrm{A}}$ ratio increased from $1 / 1$ to $2 / 1$, the extraction yield of As ${ }^{\mathrm{III}}$ increased from 85.2 to $91.0 \%$, and the time of the phase separation was prolonged from 4 to nearly $6 \mathrm{~min}$. When the ratio of $\mathrm{V}_{\mathrm{O}} / \mathrm{V}_{\mathrm{A}}$ increased further to $3 / 1$, the increase in the extraction yield of As ${ }^{\mathrm{III}}$ was not significant; however, the time of the phase separation was prolonged to nearly $7 \mathrm{~min}$, which was disadvantageous to the extraction process. Therefore, relatively speaking, $\mathrm{V}_{\mathrm{O}} / \mathrm{V}_{\mathrm{A}}=1 / 1$ was a better choice.

\section{Countercurrent Extraction Experiment}

Based on the single-stage extraction experiment, the simulated countercurrent cascade extraction experiment was conducted. Based on the Kremser-Brown-Souders equation (Szitkai et al., 2002; Ushenoy and Fraser, 2003), as shown in Equation (19), the theoretical extraction stage is calculated and determined by means of the distribution ratio, phase ratio, extraction ratio, and set value of the arsenic content in the raffinate.

$$
\varphi_{M}=\left\{\begin{array}{l}
\frac{E_{M}-1}{E_{M}^{N+1}-1} \\
\frac{1}{N+1}, E=1
\end{array}, E \neq 1\right.
$$

where $\phi_{M}$ is the fraction extracted from $M$ components, $E_{M}$ is the extraction ratio of $M$ components $\left({ }^{\circ} \mathrm{C}\right)$, and $N$ is the theoretical series.

When the ratio $\mathrm{O} / \mathrm{A}$ is $1 / 1$, the distribution ratio $D_{A s}$ of the $\mathrm{As}^{\mathrm{III}}$ extraction is calculated from Equation (13) as follows:

$$
D_{A s}=\frac{6.19}{1.07}=5.79 \text {. }
$$

Thus, the extraction ratio $E_{A s}$ is

$$
E_{\text {As }}=D_{\text {As }} \times \text { ratio }=5.79 .
$$

After the cascade countercurrent extraction, the extraction rate of $\mathrm{As}^{\mathrm{III}}$ is more than $99 \%$, and the content of $\mathrm{As}{ }^{\mathrm{III}}$ in the raffinate is as low as $0.05 \mathrm{~g} / \mathrm{l}$. Thus, the raffinate fraction $\phi_{\mathrm{As}}$ is

$\varphi_{\mathrm{As}}=\frac{\mathrm{As}^{\mathrm{III}} \text { content of the raffinate liquid }}{\mathrm{As}^{\mathrm{III}} \text { content of liquid }}=\frac{0.05}{7.26}=6.89 \times 10^{-322)}$

In conjunction with Equations (19)-(22), the theoretical stage $N$ of the extraction can be calculated:

$$
N=\frac{\lg \left(\frac{E_{A s}-1}{\phi_{A s}}+1\right)}{\lg E_{A s}}-1=2.73 \approx 3
$$

Therefore, the four-stage countercurrent cascade extraction can be used with the consideration of stage efficiency and other factors.

Under the condition of $30 \% \mathrm{CO}_{3}^{2-}$-type TOMAC $+15 \%$ secoctyl alcohol $+55 \%$ sulfonated kerosene in the organic phase, $\mathrm{V}_{\mathrm{O}} / \mathrm{V}_{\mathrm{A}}=1 / 1$, and $5 \mathrm{~min}$ extraction at room temperature, the feed solution with $\left[\mathrm{As}^{\mathrm{III}}\right]=9.69 \times 10^{-2} \mathrm{~mol} / \mathrm{l}$ and $[\mathrm{NaOH}]=$ 


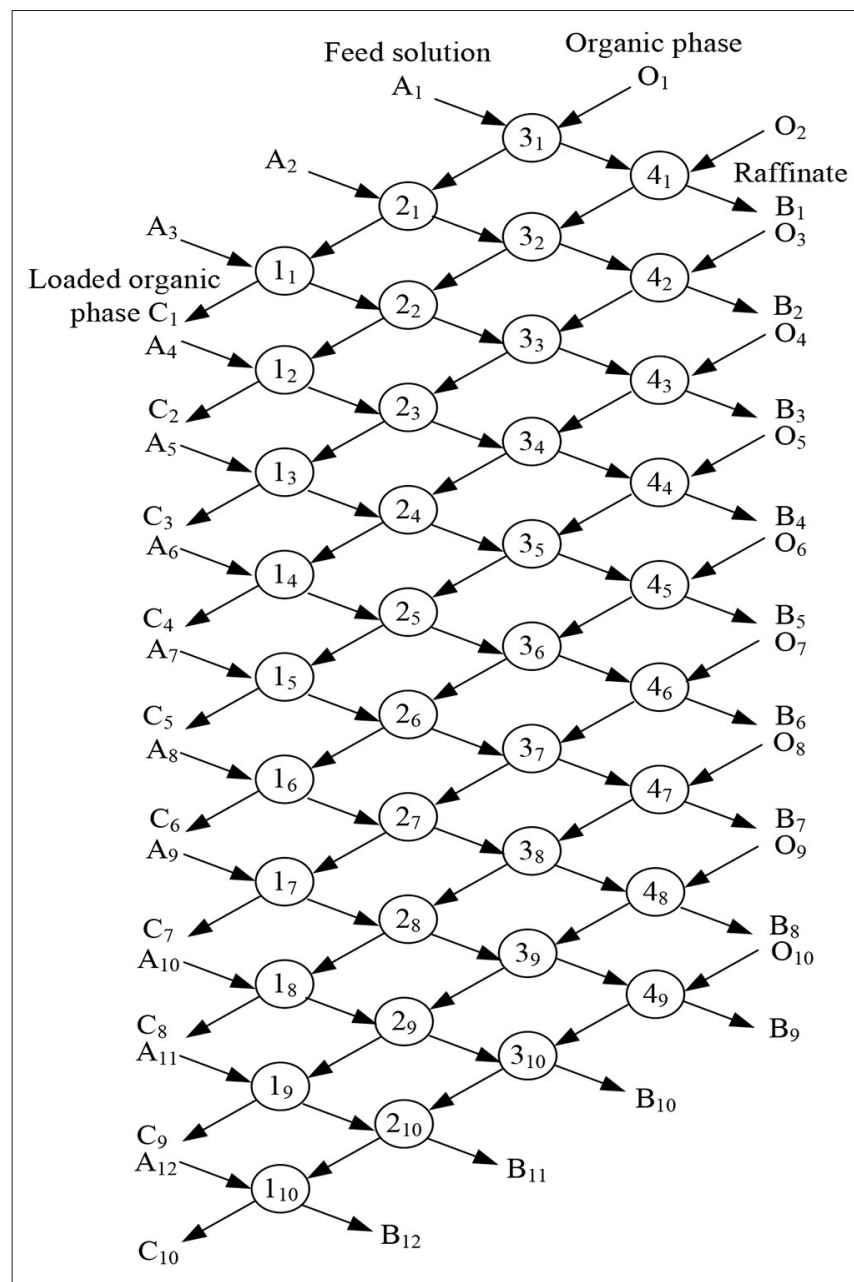

FIGURE 14 | Flow chart of four-stage countercurrent extraction.

$0.5 \mathrm{~mol} / \mathrm{l}$ was extracted by four-stage countercurrent extraction. The four-stage countercurrent extraction process is shown in Figure 14.

According to the cascade countercurrent extraction theory, the solvent extraction process can be considered to be stable only when the concentration of the extracted components tends to be stable and does not change, through the analysis of the numerous extractions in the extraction process. However, it is obviously difficult to achieve this under laboratory conditions (Ma, 2009). Practical experience shows that in the cascade countercurrent extraction experiment, when the number of rows is $\sim 3 N-2$ times of the number of stages, the extraction process will be close to equilibrium and reach a stable concentration value (Ruiz et al., 1986). Therefore, under the laboratory conditions, a total of 10 rows were carried out in the cascade extraction simulation experiment, and the raffinate of the 8,9 , and 10th rows was analyzed for As ${ }^{\mathrm{III}}$ content, with the results shown in Table 2.

As can be seen from Table 2, the results of the As ${ }^{\text {II }}$ concentration of the raffinate in rows 8,9 , and 10 are 1.34 $\times 10^{-3}, 1.01 \times 10^{-3}$, and $1.32 \times 10^{-3} \mathrm{~mol} / \mathrm{l}$, respectively,
TABLE 2 | Experimental results of four-stage countercurrent extraction.

\begin{tabular}{lcc}
\hline $\begin{array}{l}\text { Number } \\
\text { of rows }\end{array}$ & $\begin{array}{c}\text { Residual liquid concentration } \\
\text { of } \mathbf{A s}^{\text {III }}\left(\mathbf{m o l} \cdot \mathbf{I}^{-1}\right)\end{array}$ & $\begin{array}{c}\text { Four-stage countercurrent } \\
\text { extraction rate (\%) }\end{array}$ \\
\hline 8 & $1.33 \times 10^{-3}$ & 98.62 \\
9 & $1.01 \times 10^{-3}$ & 98.95 \\
10 & $1.31 \times 10^{-3}$ & 98.64 \\
\hline
\end{tabular}

exponential homogeneity, and it can be considered that the cascade extraction process reaches a steady state. Under the experimental conditions, the concentration of $\mathrm{As}^{\mathrm{III}}$ in raffinate was reduced to less than $1.33 \times 10^{-3} \mathrm{~mol} / \mathrm{l}$ after the fourstage countercurrent extraction, and the extraction rate of $\mathrm{As}^{\mathrm{III}}$ was more than $98.4 \%$. The aim of removing arsenic from alkaline medium was achieved. Therefore, the extraction of thioarsenious acid with $\mathrm{CO}_{3}^{2-}$-type TOMAC is an alternative method for arsenic removal from the alkaline leaching solution of metallurgical dust.

\section{CONCLUSIONS}

In order to improve the extraction capacity for arsenic from a high-alkali solution, TOMAC is used as an extractant. The paper proposed a $\mathrm{CO}_{3}^{2-}$-type tri-n-octylmethyl-ammonium chloride (TOMAC) method for extracting thioarsenite. TOMAC transformation and organic phase saturated extraction capacity were measured, and the extraction mechanism was preliminarily studied. The relationship between the extraction rate of $\mathrm{As}^{\mathrm{III}}$ and the number of treatments with saturated $\mathrm{NaHCO}_{3}$ was investigated. The $\mathrm{CO}_{3}^{2-}$ transformation process of TOMAC and infrared spectrum analysis before and after $\mathrm{CO}_{3}^{2-}$ transformation of TOMAC were also studied. The results show that after treating the organic phase with saturated $\mathrm{NaHCO}_{3}$ solution five times, the effective transformation of the $\mathrm{Cl}^{-}$- to $\mathrm{HCO}_{3}^{-}$-type quaternary ammonium salt can be realized, and the effective transformation of TOMAC from $\mathrm{HCO}_{3}^{-}$to $\mathrm{CO}_{3}^{2-}$ type can be achieved by alkaline washing with $1.0 \mathrm{~mol} / \mathrm{l} \mathrm{NaOH}$ solution thrice. The extraction of thioarsenite by $\mathrm{CO}_{3}^{2-}$-type TOMAC is conducted at an association molar ratio of 2:1, with the As ${ }^{\mathrm{III}}$ saturated capacity in the loaded organic phase up to $0.21 \mathrm{~mol} / \mathrm{l}$.

The study investigated the influences of extraction of thioarsenious acid by $\mathrm{CO}_{3}^{2-}$-type TOMAC, based on the volume fraction of $\mathrm{CO}_{3}^{2-}$-type TOMAC, volume fraction of 2-octanol, temperature, time, and phase ratio. With the organic phase composition of " $30 \% \mathrm{CO}_{3}^{2-}$-type TOMAC + 15\% DL-2-Octanol $+55 \%$ sulfonated kerosene," the single-stage As ${ }^{\mathrm{III}}$ extraction rate reaches $85.2 \%$ with $\mathrm{V}_{\mathrm{O}} / \mathrm{V}_{\mathrm{A}}=1 / 1$ at room temperature for $5 \mathrm{~min}$. After the four-stage countercurrent extraction, the concentration of $\mathrm{As}^{\mathrm{III}}$ in the raffinate can be reduced to less than $1.33 \times$ $10^{-3} \mathrm{~mol} / \mathrm{l}$, and the extraction rate of $\mathrm{As}{ }^{\mathrm{III}}$ can reach greater than $98.4 \%$. Hence, the extraction of thioarsenite by $\mathrm{CO}_{3}^{2-}$-type TOMAC can serve as an alternative for the removal of arsenic via alkaline leaching from high arsenic flue dust produced by heavy metal smelting. 


\section{DATA AVAILABILITY STATEMENT}

The original contributions presented in the study are included in the article/supplementary materials, further inquiries can be directed to the corresponding author/s.

\section{AUTHOR CONTRIBUTIONS}

KY: conceptualization, methodology, validation, formal analysis, investigation, writing - original draft, data curation, resources, writing - review, and editing. LL: methodology, validation, formal analysis, investigation, writing - original draft, data curation, writing - review, and editing. HZ: formal analysis. LT: writing - original draft, data curation, writing - review, and editing. ZX: supervision, project administration, resources,

\section{REFERENCES}

Asanov, D., Filyanova, L., Zapasnyi, V., and Sukhova, N. (2016). Study of the performance indices of a dust-cleaning system at the balkhash copper smelter. Metallurgist 60, 331-338. doi: 10.3389/100fnins.2013.12345

Buev, E. M., Smorodina, A. A., Stepanov, M. A., Moshkin, V. S., and Sosnovskikh, V. Y. (2018). Novel synthesis of aminoacetonitriles via the selective demethylation of quaternary ammonium salts. Tetrahedron Lett. 59, 1638-1641. doi: 10.1016/j.tetlet.2018.03.037

Chauhan, S., and Kaur, M. (2017). Modulation of aggregation behaviour of anionic surfactant in the presence of aqueous quaternary ammonium salts. J. Surfactants Deterg. 20, 599-607. doi: 10.1007/s11743-017-1949-5

Christof Lanzerstorfer, C. (2016). Flowability of various dusts collected from secondary copper smelter off-gas. Particuology 25, 68-71. doi: $10.3389 /$ fnins.2013.12345

Deiters, U. K. (2012). The isothermal van't Hoff equation for phase equilibria-a forgotten relation? Fluid Phase Equilib. 336, 22-27. doi: 10.1016/j.fluid.2012.08.028

Ermolin, M. S., Fedotov, P. S., Ivaneev, A. I., Karandashev, V. K., Burmistrov, A. A., and Tatsy, Y. G. (2019). Assessment of elemental composition and properties of copper smelter-affected dust and its nano- and micron size fractions. Environ. Sci. Pollut. Res. 26:5315. doi: 10.1007/s11356-018-3180-y

Guan, W.-J., and Zhang, G.-Q. (2011). Extraction of tungsten from simulated autoclave-soda leaching liquor of scheelite with quaternary ammonium salt. Chinese J. Nonferrous Metals 21, 1756-1762. doi: 10.1016/B978-0-444-53599-3.10005-8

Guo, X.-Y., Yi, Y., Shi, J., and Tian, Q.-H. (2016). Leaching behavior of metals from high-arsenic dust by $\mathrm{NaOH}-\mathrm{Na}_{2} \mathrm{~S}$ alkaline leaching. Trans. Nonferrous Metals Soc. China 26, 575-580. doi: 10.1016/S1003-6326(16)64118-3

Hoffmann, J. E. (1993). Remediating copper smelter dusts: the arsenic problem. J. Miner. Metals Mater. Soc. 45, 30-31. doi: 10.1007/BF032 22401

Jarošíková A., Ettler, V., Mihaljevič, M., Drahota, P., Culka, A., and Racek, M. (2018). Characterization and ph-dependent environmental stability of arsenic trioxide-containing copper smelter flue dust. J. Environ. Manage. 209, 71-80. doi: 10.1016/j.jenvman.2017.12.044

Karimov, K., and Naboichenko, S. (2016). Sulfuric acid leaching of high-arsenic dust from copper smelting. Metallurgist 60, 456-459. doi: 10.1007/s11015-016-0313-8

Larkin, P. J. (2011). Infrared and Raman Spectroscopy-Principles and Spectral Interpretation. Stamford, CT: Elsevier.

Liu, W.-F., Fu, X.-X., Yang, T.-Z., Zhang, D.-C., and Chen, L. (2018). Oxidation leaching of copper smelting dust by controlling potential. Trans. Nonferrous Metals Soc. China 28, 1854-1861. doi: 10.1016/S1003-6326(18)64830-7

Liu, Z.-H., Zhang, P., Li, Y.-H., Liu, Z.-Y., and Li, L. (2009). Study on leaching dearsenication from waltz zinc oxide containing high as by $\mathrm{Na}_{2} \mathrm{~S}-\mathrm{NaOH}$ mixed alkali. Hydrometall. China 28, 229-232. doi: 10.13355/j.cnki.sfyj.2009. 04.011 funding acquisition, writing - review, and editing. RW: supervision, writing - review, and editing. All authors contributed to the article and approved the submitted version.

\section{FUNDING}

Financial support was provided by the National Nature Science Foundation of China (nos. 52074136, 51904124, 51804136, and 51764016), the Distinguished Professor Program of Jinggang Scholars, China Institutions of Higher learning Jiangxi Province, China, the Jiangxi Province Nature Science Foundation (no. 20181BAB216017), the Jiangxi Science and Technology Landing Project (no. KJLD13046), and the Research Fund Program of State Key Laboratory of Rare Metals Separation and Comprehensive Utilization (no. GK-201803).
Ma,. R.-J. (2009). Extractive Metallurgy. Beijing: Metallurgical Industry Press.

Montenegro, V., Sano, H., and Fujisawa, T. (2013). Recirculation of high arsenic content copper smelting dust to smelting and converting processes. Miner. Eng. 49, 184-189. doi: 10.1016/j.jenvman.1272017.12.044

Morales, A., Cruells, M., Roca, A., and Bergó, R. (2010). Treatment of copper flash smelter flue dusts for copper and zinc extraction and arsenic stabilization. Hydrometallurgy 105, 148-154. doi: 10.1016/j. hydromet.2010.09.001

Rappas, A., Falls, C., and Waterman, B. T. (1990). Processes for the Treatment of Smelter Flue Dust. U.S. Patent No 4,891,067. Wilmington, DE: US Patent.

Reynolds, J. E. (1981). Process for Recovery Arsenic Compouds by Sodium Hydroxide Leaching. U.S. Patent No 4,244,927. Denver, CO: US Patent.

Richards, O. W. (1926). A nomogram for the van't hoff-arrhenius temperature equation. J. Phys. Chem. 30, 1219-1221.

Ruiz, F., Marcilla, A., and Gomis, V. (1986). Method for equilibrium-stage calculations in liquid extraction. application to countercurrent cascade design for a quaternary system. Indus. Eng. Chem. Process Design Dev. 25, 631-634.

Sahu, N. K., Dash, B., Sahu, S., Bhattacharya, I. N., and Subbaiah, T. (2012). Extraction of copper by leaching of electrostatic precipitator dust and two step removal of arsenic from the leach liquor. Korean J. Chem. Eng. 29, 1638-1642. doi: 10.1007/s11814-012-0081-5

Sanchez de la Campa, A., de la Rosa, J., Sánchez-Rodas, D., Oliveira, V., Alastuey, A., Querol, X., et al. (2008). Arsenic speciation study of pm2.5 in an urban area near a copper smelter. Atmos. Environ. 42, 6487-6495. doi: 10.1016/j.atmosenv.2008.04.016

Suflet, D., Popescu, I., Pelin, I., Nicolescu, A., and Hitruc, G. (2015). Cationic curdlan: synthesis, characterization and application of quaternary ammonium salts of curdlan. Carbohydr. Polym. 123, 396-405. doi: 10.1016/j.carbpol.2015.01.050

Szitkai, Z., Lelkes, Z., Rev, E., and Fonyo, Z. (2002). Handling of removable discontinuities in minlp models for process synthesis problems, formulations of the kremser equation. Comp. Chem. Eng. 26, 1501-1516. doi: 10.1016/S0098-1354(02)00037-6

Ushenoy, U. V., and Fraser, D. M. (2003). A new formulation of the kremser equation for sizing mass exchangers. Chem. Eng. Sci. 58, 5121-5124. doi: $10.1016 /$ j.ces.2003.08.007

Uslu, H. (2008). Extracion of citric acid in 2-octanol and 2-propanol solutions containing tomac: an equilibria and a LSER model. Braz. J. Chem. Eng. 25, 553-561. doi: 10.1590/S0104-66322008000300013

Weisshaar, D. E., Earl, G. W., Amolins, M. W., Mickalowski, K. L., Norberg, J. G., and Rekken, B. D. (2012). Investigation of the stability of quaternary ammonium methyl carbonates. J. Surfactants Deterg. 15, 199-205. doi: 10.1007/s11743-011-1292-1

Wu, Q., Liu, C.-L., Yang, J.-C., Guan, A.-Y., and Ma, H.-J. (2017). Design, synthesis, and herbicidal activity of novel quaternary ammonium salt derivatives. Pest. Biochem. Physiol. 143, 246-251. doi: 10.1016/j.pestbp.2017.05.006

$\mathrm{Xu}$, Z.-F., Zhang, X.-K., and Zhao, H.-X. (2016). Thermodynamics of sulfidation of arsenite in alkaline solutions. Nonferrous Metals 7, 5-8. doi: 10.3969/j.issn.1007-7545.2016.07.002 
Xu, Z.-H., Li, Q., and Nie, H.-P. (2010). Pressure leaching technique of smelter dust with high-copper and high-arsenic. Trans. Nonferrous Metals Soc. China 20, 176-181. doi: 10.1016/S1003-6326(10)60035-0

Yang, T., Fu, X., Liu, W., Chen, L., and Zhang, D. (2017). Hydrometallurgical treatment of copper smelting dust by oxidation leaching and fractional precipitation technology. JOM 69, 1982-1986. doi: 10.1007/s11837-0172492-6

Zheng, Y.-J., Liu, W.-Y., Bai, M., B., and Zhang, C.-F. (2008). Preparation of arsenic trioxide from arsenic sulfide slag. J. Central South Univ. 9, 1157-1163.

Zhu,. T. (2005). Extraction and Ion Exchange. Beijing: Metallurgical Industry Press.
Conflict of Interest: The authors declare that the research was conducted in the absence of any commercial or financial relationships that could be construed as a potential conflict of interest.

Copyright (C) 2021 Yan, Liu, Zhao, Tian, Xu and Wang. This is an open-access article distributed under the terms of the Creative Commons Attribution License (CC BY). The use, distribution or reproduction in other forums is permitted, provided the original author(s) and the copyright owner(s) are credited and that the original publication in this journal is cited, in accordance with accepted academic practice. No use, distribution or reproduction is permitted which does not comply with these terms. 